\title{
Epidemiological and Forensic Aspects of Physical Abuse of Minors
}

\author{
Ndoye El Hadji Oumar ${ }^{*}$, Diallo Amadou Mouctar ${ }^{2}$, Camara ${ }^{2}$, Conde \\ Namoudou $^{2}$, Dia Sidy Ahmed ${ }^{1}$ and Soumah Mouhamed Manibiliot ${ }^{1}$ \\ ${ }^{1}$ Forensic and Labor Medicine Department, Cheikh Anta Diop Dakar University (UCAD), Senegal \\ ${ }^{2}$ Forensic Department, Ignace Deen Hospital, Conakry
}

*Corresponding author: Ndoye El Hadji Oumar, Forensic and Labor Medicine Department, Cheikh Anta Diop Dakar University (UCAD), Dakar, Senegal, Email: omar.ndoy@yahoo.com

\section{Research Article \\ Volume 6 Issue 1}

Received Date: December 16, 2020

Published Date: January 04, 2021

DOI: $10.23880 /$ ijfsc- 16000217

\section{Abstract}

Child abuse is a phenomenon whose magnitude remains unknown in Africa. It includes all forms of physical and/or emotional abuse, sexual abuse, neglect or negligent treatment, or commercial exploitation.

This is a prospective descriptive study, with systematic case-by-case recruitment of victims of physical abuse of minors received in the forensic medicine department of the Ignace Deen National Hospital over a twelve (12) month period, from July 20, 2016 to July 19, 2017.

The study included 218 cases of child abuse out of 1110 patients who were seen for any reason, a proportion of $20 \%$. Victims aged between 11 and 15 years old were the most represented with $46.7 \%$ and more than half were out of school with $59.6 \%$, girls were the most represented in our study with $73.3 \%$ with a sex ratio $\mathrm{M} / \mathrm{F}=0.36$. The relationship between the victim and the aggressor was familial in (44\%). The injuries were found all over the body. $77.60 \%$ of the victims had a total work disability of less than or equal to 20 days.

Physical abuse is common in Conakry. Young subjects are the most affected, especially student summary. Minors constitute a fragile population, dependent and vulnerable to the assaults to which they are subjected, both inside and outside the family sphere.

Keywords: Corporal Abuse; Minors; Epidemiological and Medical Aspects; Lega-Maltreatment; Abuse

Abbreviations: WHO: World Health Organization; ODAS: Observatory of Decentralized Social Action; ICRC: International Convention on the Rights of the Child.

\section{Introduction}

The child population is exposed to violence because of its vulnerability. Faced with an adult or an older minor, a child is a fragile being. Among the forms of abuse to which a minor may be subjected, the most frequently discussed in the literature is maltreatment [1].
According to the World Health Organization (WHO), maltreatment is any form of abuse and neglect of any person under the age of 18. It includes all forms of physical and/or emotional maltreatment, sexual abuse, neglect or negligent treatment, or commercial or other exploitation, resulting in actual or potential harm to the child's health, survival, development or dignity, in the context of a relationship of responsibility, trust or power [1].

Child maltreatment can take many forms: physical abuse, Silverman syndrome, sexual abuse, shaken baby syndrome, 


\section{International Journal of Forensic Sciences}

neglect, emotional abuse, vicarious Munchausen syndrome [2].

Indeed, the 20th century is marked by a strong interest in children, their rights, their personal development and their contribution to future societies.

Article 3 of the International Convention on the Rights of the Child (CRC) states: «In all actions concerning children, whether undertaken by public or private social welfare institutions, courts of law, administrative authorities or legislative bodies, the best interests of the child shall be a primary consideration». This formulation is taken up and even reinforced in the law of 5 March 2007 reforming the protection of children, which states that: «The interests of the child, the consideration of his or her basic physical, intellectual, social and emotional needs and the respect of his or her rights must guide all decisions concerning him or her» [3].

There are currently in Guinea specific legislative texts on child abuse (Article 340 to Article 352 of the C.P.G.C.), certain general texts relating to intentional assault and battery (Article 295 to Article 305 of the C.P.G.C.) and indecent assault (Article 321 to Article 325 of the C.P.G.C.).

However, abuse is a phenomenon whose extent remains unknown, which is discussed in the media and the public mainly from the angle of the miscellaneous fact and in front of which professionals are poorly equipped to solve fundamental questions such as: how to define and identify abuse? How to assess the seriousness of the situations encountered? What to expect from the family of a child suspected of being abused [4]?

Approximately $20 \%$ of women and $5-10 \%$ of men worldwide report having been sexually abused as children, and $23 \%$ of people report having been physically abused as children» [5]

In its 2003 annual report, the Observatory of Decentralized Social Action (ODAS), together with the Child Welfare Agency (ASE), listed 86,000 children at risk, 18,300 of whom were considered to be really abused, two-thirds of whom were under the age of 4 years: of these 5,600 were physically abused, 5,900 were sexually abused, 5,000 were severely neglected, and 2,000 were psychologically abused $[6,7]$.

In France, every year, 95,000 children are reported as being in danger of abuse, 19,000 of whom are abused [8]. Thus, the concern to protect the child, the short, medium and long term consequences and the need to make this phenomenon better known motivated the choice of this theme entitled: Physical abuse of minors: epidemiological and forensic aspects in Conakry.

In order to carry out this work, we set ourselves the objectives of determining the frequency of physical abuse of minors in Conakry, describing the epidemiological profile of abused minors as well as the traumatic injuries, and evaluating the total work incapacity.

\section{Methodology}

\section{Type and Duration of Study}

This was a one-year descriptive prospective study from July 20, 2016 to July 19, 2017 conducted at the Forensic Medicine Department of the Ignace Deen National Hospital (CHU Conakry). This is the only referral service in Guinea that deals with medico-legal cases.

\section{Target Population}

During this period, we collected all victims of physical abuse of minors from 1110 patients received in forensic medical consultation in the service.

The target population consisted of all victims of violence in the Conakry region.

\section{Study Population}

It consisted of all children under 18 years of age who were victims of violence during the study period, received and consulted at the forensic medicine service.

- Inclusion Criteria: All children under 18 years of age who were victims of violence and who had been consulted for forensic medical expertise to go to court were included in this study.

- Exclusion criteria: All children under the age of 18 who were victims of violence and who had not been the subject of a complaint were excluded.

\section{Data Collection Methods and Analysis Plan}

Survey forms were completed as and when a victim met our selection criteria.

The counting was done on the basis of epi info 7.1; word processing was done using Microsoft Office 2013 software.

\section{Limitation of the Study}

An important limitation to our knowledge is the ignorance of the sanctions retained against the perpetrators of such offences when they are charged. 


\section{Results}

\section{Frequency}

Thus, we counted 218 victims of physical abuse of minors out of a total of 1110 patients, i.e. a proportion of $20 \%$.

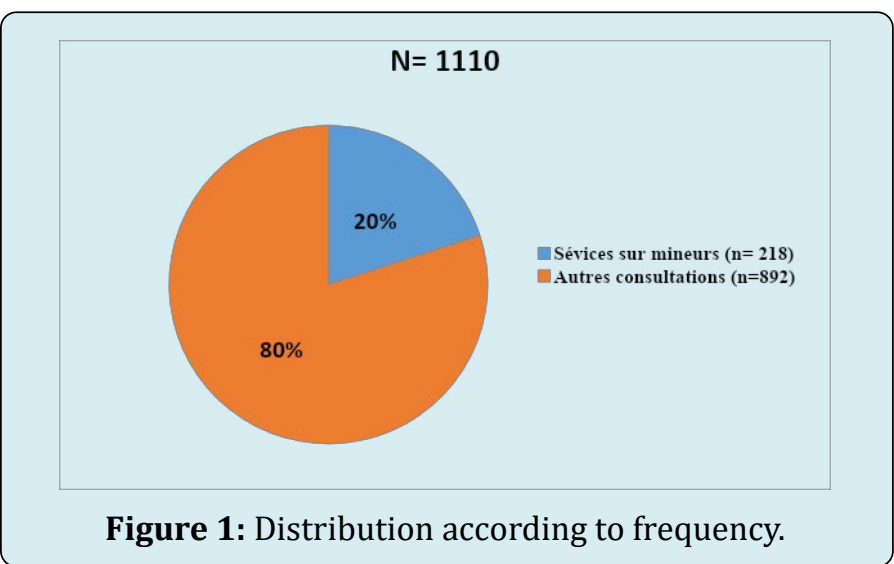

\section{Age}

In our study, the age group between 11 and 15 years, or $46.7 \%$, was the most affected. The average age was 13 years with extremes ranging from 1 to 17 years.

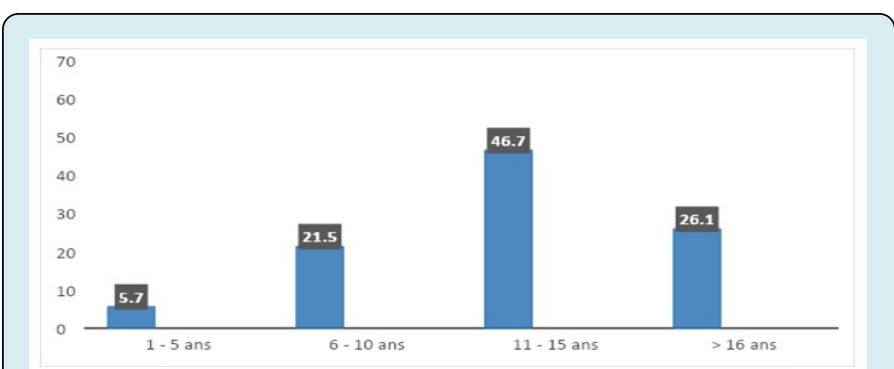

Figure 2: Distribution of victims of abuse by age group.

\section{Gender}

The female sex was the most represented with $73.3 \%$ with a sex ratio (male / female) equal to 0.36

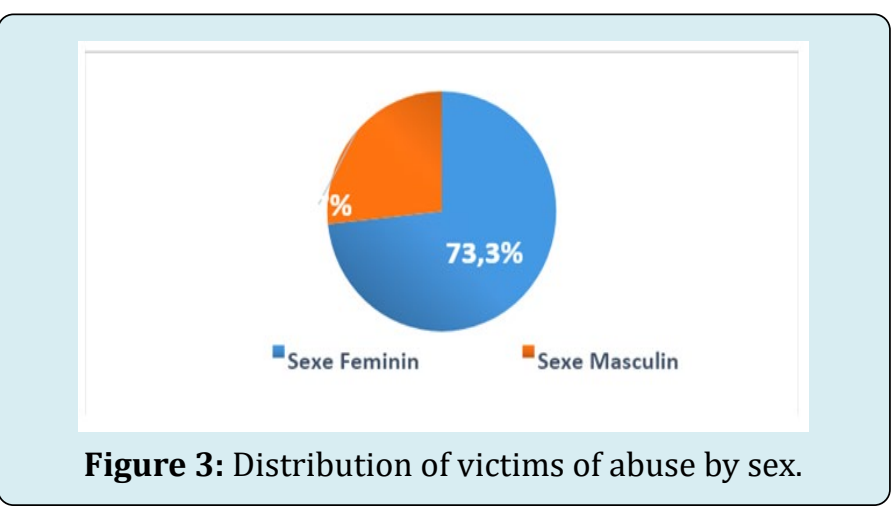

\section{Link with the Victim}

In our work, $52 \%$ of our abused patients had a family connection with the abuser.

\begin{tabular}{|c|c|c|}
\hline Link with the author & Effective & Percentage \\
\hline Family & 97 & 52 \\
\hline Extra-familial & 55 & 28 \\
\hline None & 40 & 20 \\
\hline Total & 218 & 100 \\
\hline
\end{tabular}

Table 1: Distribution of victims of abuse according to link with the aggressor.

\section{Types of Lesions}

We found $40 \%$ of lesions located in the lower limbs, followed by $30 \%$ located in the head, $24 \%$ in the upper limbs.

\begin{tabular}{|c|c|c|}
\hline Site of lesions & Effective & Percentage \\
\hline Head & 65 & 30 \\
\hline Upper members & 53 & 24 \\
\hline Legs & 87 & 40 \\
\hline Trunk & 2 & 1 \\
\hline Genital region & 11 & 5 \\
\hline Total & 218 & 100 \\
\hline
\end{tabular}

Table 2: Distribution of victims according to the site of the lesions.

\section{Blunt Agent}

Blunt agents were the most used by aggressors, ie $83.4 \%$.

\begin{tabular}{|c|c|c|}
\hline Instrument type & Effective & Percentage \\
\hline Blunt & 182 & 83,4 \\
\hline Spicy & 8 & 3,6 \\
\hline Sharp & 20 & 9,1 \\
\hline Thermal & 6 & 3 \\
\hline Chemical & 2 & 0,9 \\
\hline Total & 218 & 100 \\
\hline
\end{tabular}

Table 3: Distribution of victims according to the vulnerable agent.

\section{Complications of Abuse}

In our study we found psychological abuse on all victims $(100 \%)$ followed by physical abuse $55.5 \%$ and sexual seal $44.5 \%$. 


\begin{tabular}{|c|c|c|}
\hline Type of violence & Effective & Percent\% \\
\hline Psychologica & 218 & 100 \\
\hline Physical & 121 & 55,5 \\
\hline Sexual & 97 & 44,5 \\
\hline Negligence & 2 & 0 \\
\hline
\end{tabular}

Table 4: Breakdown of victims according to the type of abuse encountered.

\section{Forensic Aspects}

Out of 218 victims of abuse, $77.60 \%$ received a criminal ITT of 20 days or less.

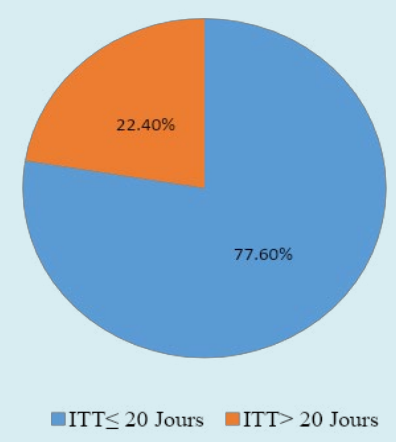

Figure 4: Distribution of victims according to ITT in the criminal sense.

\section{Discussion}

\section{Frequency Distribution}

Out of a total of 110 patients received in forensic medical consultation, Each year (D1), approximately 50,000 complaints are filed for physical abuse of children and 20,000 for sexual abuse (D2). We counted 218 victims of physical abuse of minors, i.e. a proportion of $20 \%$. This relatively low frequency in our work could be explained by the silence of maltreated children when they are old enough to talk, by the usual denial of parents when abuse is discovered or revealed by the child, or by the difficulty of professionals in recognizing it, and their reluctance to report it once it is recognized $[9,10]$.

\section{Age Distribution of Victims of Abuse}

In our study, the age group between 11 and 15 years of age $(46.7 \%)$ was the most affected.

Lolita [11] reported that the 10-15 year age group was the most common age group with extremes of 11 months to
15 years.

The predominance of this age group is explained on the one hand by the fact that it corresponds to adolescence, which is marked by puberty, curiosity, sexuality, etc., which often leads to psychosis, drug use, delinquency, etc., resulting in learning failures and difficulties in relationships with their guardians.

But also it is the young people of this age who are regularly on the street begging or selling objects, even in places of distraction, who suffer the most aggression.

\section{Distribution of Victims of Abuse by Gender}

The female sex was the most represented with $73.3 \%$ with a sex ratio (man/woman) equal to 0.36 . These results are in agreement with the data in the literature on child abuse, which reports a predominance of female victims [8,12-14].

This could be explained by the fact that Guinea is a country where the rate of violence against girls and children is high, with different proportions depending on the type of violence perpetrated, but traditionally men only consider and recognize women and their usefulness by marrying and having children.

\section{Distribution of Abuse Victims by Relationship to the Abuser}

The predominance of intra-familial violence among minors is known [15] and was described as early as 1860 by Tardieu [16].

In our work $51.84 \%$ of our patients were victims of their guardian.

- In France, 2013, Lolita in her PhD thesis on minors who are victims of violence reported that victims designated a family member as the perpetrator in $53.7 \%$ of total cases (415/682) [11]. This result shows that corporal abuse of children is intrafamilial violence in which the parents deny any abusive intention in their acts, justifying them as an educational necessity imposed by a particularly rebellious child or as corporal punishment enshrined in traditions.

- Distribution of victims according to the location of the injuries: In $30 \%$ of the victims the lesions were located in the head, this result testifies to the mobility and the easily accessible situation of the head making it a target of first choice. 


\section{International Journal of Forensic Sciences}

\section{Type of Instrument}

Blunt agents were the most frequently used, i.e. 83.4\%. This result could be explained by the fact that they are the most accessible because of their daily use and are within everyone's reach.

\section{Type of Abuse}

In our study we found $100 \%$ psychological abuse followed by physical abuse $55.5 \%$ and sexual abuse $44.5 \%$. This result shows that each type of abuse is accompanied first by psychological abuse because where the workers talk about abuse, the parents talk about education without feeling the slightest doubt or guilt.

Psychological mistreatment accompanies physical and sexual violence or serious negligence. But it can also be isolated, the child suffering from rejection, abandonment, threats, devaluation, blatant injustice, or even more actively mental cruelty. It jeopardizes the emotional and social development of the child, the relational harmony necessary for his or her development and possibly the very structuring of his or her personality [17]. This leads, beyond physical and psychological injuries, to confusion, loss of reference points and control, and cognitive distortions. This confusion is further increased by threats of reprisals and death.

\section{Distribution of Victims of Abuse According to total work Disability or TWD}

TTI may seem difficult to assess in a child, especially if it is an infant. The determination of this TWD is based on the limitation of the individual's daily activities, regardless of age, due to trauma. Thus, for an infant, it can be a question of feeding, having contact with another individual, smiling, babbling... The more the child grows, the easier the determination of this TWD becomes because it is possible to ask simple questions to the child about what he can or cannot do. Despite the term "work disability», it is not related to work activity and it is therefore quite possible to determine a TWD in a child. For example, $77.60 \%$ of children had a TWD of 20 days or less.

This result shows the low seriousness of the violence and will be qualified as a crime.

In case of a finding of child abuse, the protection of the child takes precedence over the writing of the certificate and it is recommended to hospitalize the child, in order to remove him/her from danger and to carry out a multidisciplinary evaluation (social, psychological, medical, judicial). It is recommended to focus on detecting a possible slowdown in psycho-emotional development and its pathological nature, and to explore all dimensions of development. The child's words should be listened to with caution and if possible, initially in the absence of the parents. When conducting the psychological assessment, since the child is suggestible and highly undecided, it is recommended that the interview not be conducted or directed, and that the child be allowed to express himself or herself in his or her own way, not to ask closed questions, to ask simple questions, to never suggest a particular event or symptom, and not to ask the same question twice. It is then recommended, as much as possible, to refer the child to a specialized unitê. Except in an emergency, the referral can be réalisê secondarily, the main thing being that the referral should be réalisẽ.

The duration of the TWD will determine the consequences of the criminal procedure: qualification of the offence, applicable penalties, mode of prosecution according to different thresholds (less than, equal to or more than 20 days; less than, equal to or more than 3 months).

\section{Conclusion}

Child abuse is a real public health problem and faces difficulties, partly due to a lack of consistency in definitions. Minors are a fragile population, dependent and vulnerable to abuse, both outside and within the family sphere. Thus, they must receive judicial and medico-social treatment appropriate to their condition and to the potentially serious and lasting consequences on their psychological, emotional, relational and social development that result from such aggressions, especially when they are of a sexual nature.

Sexual violence against minors, which is endemic, has serious consequences on a somatic and psychological level. The medical examination, which is very specialized, is always useful in a context of sexual violence against a minor. However, it has limits and these limits must be known not only by doctors but also by all the professionals involved: investigators, magistrates and lawyers.

With the aim of protecting the child, the role of the doctor is primordial in the detection of child abuse, the diagnostic orientation and the often difficult differential diagnosis, the particularities of the clinical examination and the medicojudicial implications of the report.

\section{References}

1. WHO (2013) Child abuse. World Health Organization.

2. Jenny C (2008) Medicine discovers child abuse. JAMA J Am Med 300(23): 2796-2797.

3. (1989) International Convention on the Rights of the Child. United Nation Human Rights 236: 80. 


\section{International Journal of Forensic Sciences}

4. (1998) National Assembly of the Republic Of Guinea. Law $\mathrm{N}^{\circ} 98 / 036$ of December 31, 1998 on the penal code of the Republic of Guinea, pp: 295-300.

5. (2013) Child abuse by the WHO. Health educationHealth, social action: figures. Eduscol.

6. ODAS (2003) The letter from the Observatory of Decentralized Social Action (ODAS).

7. Underwood E (2015) Measuring child abuse's legacy. Science 347(6229): 1408.

8. Sibertin-Blanc D, Vidailhet C, Martrille L (Forensic Pathologist), Visier JP, Maury M (2008) Abuse and childhood in danger: Redaction, pp: 103.

9. ONPE (2015) Data from the collaboration between the Ministerial Statistical Service for Internal Security on crimes and offenses recorded by the police or gendarmerie services and the National Child Protection Observatory.

10. ONPE (2017) Data from the collaboration between the Ministerial Statistical Service of Internal Security on crimes and offenses recorded by the police or gendarmerie services and the National Child Protection
Observatory (ONPE). Eleventh and Twelfth Report to the Government and Parliament of the ONPE.

11. Lolita L (2011) State Doctorate Thesis in Medicine: Minors victims of violence: medico-legal elements and legal consequences. Analysis of 682 cases.

12. Husson F, Josse J (2013) Handling missing values in multiple factor analysis. Food Qual Prefer 30(2): 77-85.

13. Terri L Messman Moore, Patricia J Long (2000) Child Sexual Abuse and Revictimization in the Form of Adult Sexual Abuse, Adult Physical Abuse, and Adult Psychological Maltreatment. Journal of Interpersonal Violence 15(5): 2000.

14. Damashek A, Nelson MM, Bonner BL (2013) Fatal child maltreatment: Characteristics of deaths from physical abuse versus neglect. Child Abuse Negl 37(10): 735-744.

15. Manoudi F, Chagh R, Soussi MES, Asre F, Tazi I (2013) Family Violence. The Encephalus, pp: 271-277.

16. Tardieu A (2008) Medical-Legal study on abuse and mistreatment of children. Childhood Psy 39(2): 174-178.

17. Vila G, Porche LM, Mouren Simeoni MC (1998) The Child Victim of Aggression, Masson, Paris. 